\title{
Relação do emprego, da renda e das variáveis político-monetárias com as decisões de modalidades de crédito
}

Bruna Rafaella Vasconcelos do Nascimento

Membro do Grupo de Pesquisa "Inteligência em Finanças e Mercados" (CNPQ/UFU). Administradora pela Universidade Federal de Uberlândia (UFU).

E-mail: bruna_vasconcelos_15@hotmail.com

Odilon Jose de Oliveira Neto

Doutor em Administração pela Fundação Getulio Vargas (FGV/EAESP). Professor de Finanças do Curso de Administração da Universidade Federal de Uberlândia (UFU). Líder do Grupo de Pesquisa "Inteligência em Finanças e Mercados" (CNPQ/UFU). Membro do Núcleo de Educação Financeira (NEF-UFU).

E-mail: odilonoliveira@ufu.br

\section{Simone Oliveira Rezende}

Mestre em Economia pela Universidade Federal da Paraíba (UFPB). Professora de Economia e Finanças do Instituto Aphonsiano de Ensino Superior (IAESup). Membro do Grupo de Pesquisa "Inteligência em Finanças e Mercados" (CNPQ/UFU).

E-mail: sreoli@yahoo.com

\section{Victor Manuel Barbosa Vicente}

Doutor em Administração pela Universidade de Brasília (UNB). Membro do Grupo de Pesquisa "Inteligência em Finanças e Mercados" (CNPQ/UFU). Membro do Núcleo de Educação Financeira (NEF-UFU).

E-mail: victorvicente@ufu.br

Resumo: Este estudo teve por objetivo verificar a relação entre variáveis políticomonetárias, trabalho e renda com as decisões quanto à modalidade de crédito das pessoas físicas no Brasil no período de abril de 2007 e janeiro de 2016. O estudo compreende a aplicação de análise de correlação e de regressão múltipla. A partir da análise de regressão averiguou-se a relação entre as variáveis dependentes: cartão de crédito (rotativo, à vista e parcelado), crédito (não consignado e consignado), cheque especial e variáveis independentes: recolhimento de compulsórios, papel moeda em poder do público, saldo de títulos públicos, renda, taxa de desemprego, taxa de inflação, Produto Interno Bruto (PIB), Índice Geral de Preços do Mercado, taxa de câmbio e taxa SELIC. Os resultados da análise de regressão apontam que as variáveis que mais influenciam as decisões nas modalidades de crédito são: o PIB, o papel moeda em poder público, a renda, o saldo dos títulos públicos e a taxa de câmbio.

Palavras chaves: Modalidades de Crédito; Política Monetária; Renda

Abstract: This study aimed to verify the relationship between political and monetary variables, the work and income with the decisions regarding credit mode of individuals in Brazil during the 
p. 39 - Relação do emprego, da renda e das variáveis político-monetárias com as decisões de modalidades de crédito

period from April 2007 to January 2016. The study comprises the application of correlation analysis and multiple regression. From the regression analysis was the relationship between the dependent variables: credit card (revolving, and installment), credit (not recorded and recorded), overdraft and independent variables: compulsory recall, paper currency in public power, balance of government bonds, income, unemployment rate, inflation rate, gross domestic product (GDP), General market price Index, exchange rate and rate SELIC. The results of the regression analysis indicate that the variables that more influence the decision by credit mode are: GDP, the paper money in government income, the balance of government bonds and the exchange rate.

Key words: Types of Credit; Monetary Policy; Income.

JEL Code: D14

\section{INTRODUÇÃO}

Desde o início da década de 1990 vem sendo adotada no Brasil políticas que proporcionam maior acesso ao crédito, em especial a partir do Plano Real, que inicialmente contribuiu para uma maior estabilidade econômica e redução da inflação. Ao observar a forte expansão do volume de empréstimos e financiamentos no Brasil, remete-se à importância da análise do crédito, que direta ou indiretamente corrobora com o crescimento da economia brasileira e aquecimento do mercado consumidor.

Dados do Banco Central do Brasil (representado pela sigla: BCB ou BACEN) mostram que a relação Crédito/PIB foi de 23,8\% em dezembro de 2002 e 55,8\% em fevereiro de 2014, o que mostra o crescimento expressivo do mercado de crédito no Brasil em relação à riqueza acumulada na produção de bens e serviços. (BACEN, 2014). Neste contexto, vale destacar que, principalmente a partir do ano de 2007, tem-se um expressivo aumento do volume de crédito disponível para as pessoas físicas, o que hipoteticamente levou os bancos a concederem mais empréstimos e financiamentos e colaborou para que as instituições financeiras atingissem altos retornos, principalmente devido à enorme diferença entre os juros que remuneram os correntistas/investidores e os juros pagos pelos agentes que necessitam dos empréstimos/financiamentos, sobretudo quando comparado aos empréstimos/financiamentos tomados por pessoas jurídicas. Essa diferença é conceituada como spread bancário.

Nesse sentido, o crédito se coloca como uma ferramenta fundamental na realização de transações comerciais, isto é, para as pessoas jurídicas que precisam de recursos para investir em suas atividades de produção, comerciais e ou de serviços, e para as pessoas físicas que precisam atender suas necessidades, recorrendo, assim, ao crédito disponibilizado para empréstimos e financiamentos pelas instituições financeiras, sendo ambas atraídas pelo conjunto, taxas de juros mais baixas e necessidade de liquidar suas dívidas.

Segundo Sandroni (1999, p. 140), crédito é uma "transação comercial em que um comprador recebe imediatamente um bem ou serviço adquirido, mas só fará o pagamento depois de algum tempo determinado." Assim sendo, várias modalidades de crédito foram criadas, aperfeiçoadas e ampliadas ao longo do tempo, dentre as quais se destacam as seguintes: cheque especial, cartão de crédito, empréstimo pessoal, crédito 
Bruna R. V. do Nascimento; Odilon J. de Oliveira Neto; Simone O. Rezende e Victor M. B.

direto ao consumidor, crédito consignado em folha de pagamento, crédito habitacional e leasing.

Em teoria, nos períodos de crise econômica, tem-se uma queda das operações de crédito, principalmente devido às altas taxas de juros, volatilidade da taxa de câmbio, dentre outros fatores, o que pressupõe possíveis alterações na escolha pela modalidade de crédito. Essa verificação é corroborada por Douat (1994) e Schrickel (1995), que apontam que o crédito envolve a concedente um risco significativo e que as empresas buscam minimizar este risco. Sobre isso, destaca-se ainda que o risco possa ser encontrado em diversas atividades comerciais, inclusive na decisão de modalidades de crédito, caracterizada pela probabilidade do não recebimento dos empréstimos e/ou financiamentos agregado aos demais custos provenientes da transação.

Diante disso, é relevante destacar as políticas monetárias que decorrem da atuação de autoridades monetárias sobre a quantidade de moeda em circulação e outras importantes variáveis, com destaque para: as taxa de juros, a inflação e o câmbio. Além das variáveis monetárias, teoricamente tem-se a renda e a taxa de desemprego como importantes elementos para definição do crédito.

Segundo Tavares, Montes e Guílen (2013), o crédito é um canal de transmissão importante da política monetária. Dessa forma, a concessão de crédito às pessoas físicas vem se tornando um problema para uma parcela significativa de pessoas jurídicas. Isso se deve ao fato de que o aumento da concessão de crédito implica em maiores níveis de endividamento das pessoas físicas, e pode causar impactos significativos na capacidade de pagamento e consequentemente no planejamento familiar. É neste contexto que emerge a seguinte questão: qual a relação entre as variáveis político-monetárias e do emprego e renda com as principais modalidades de crédito?

A justificativa desse estudo perpassa pela importância dessa pesquisa para auxiliar à tomada de decisões adequadas sobre modalidades de crédito de pessoas físicas, o que de certa forma contribuiria para a minimização dos riscos de endividamento. Assim sendo, espera-se que os resultados dessa pesquisa auxiliem às tomadas de decisões empresariais, principalmente devido às estimativas sobre os impactos das políticas monetárias, do emprego e da renda na decisão pela modalidade de crédito por parte dos clientes, o que de certa forma pode contribuir para a redução dos índices de inadimplência e dos seus consequentes prejuízos.

Assim sendo, esse estudo teve como objetivo principal verificar a relação entre variáveis político-monetárias, o trabalho e a renda e as decisões quanto à modalidade de crédito das pessoas físicas no Brasil no período de abril de 2007 a janeiro de 2016.

\section{REVISÃO DE LITERATURA}

Tavares, Montes e Guílen (2013, p. 338) dizem que "a literatura tradicional relacionada aos mecanismos de transmissão da política monetária geralmente enfatiza cinco canais de transmissão: taxa de juros, taxa de câmbio, preços de ativos, crédito e expectativa", e recentemente aumentou-se a necessidade de focar os estudos no canal de crédito. Neste contexto, um dos principais precursores dos estudos sobre o crédito e 
p. 41 - Relação do emprego, da renda e das variáveis político-monetárias com as decisões de modalidades de crédito

sua relação com políticas monetárias foi Yeager (1974), que realizou sua pesquisa no período pós-guerra nos Estados Unidos. A partir do uso da análise de regressão linear o autor concluiu que $94 \%$ dos consumidores norte-americanos, por não controlarem suas dívidas de acordo com a renda, se tornam inadimplentes, sendo essa a principal variável que justifica o endividamento.

Aproximadamente uma década após o estudo de Yeager (1974) e, Gertler e Gilchrist (1993) apontaram como as imperfeições do mercado de crédito podem desempenhar um papel importante na transmissão da política monetária. Os resultados apontaram que há uma diferença marcante em resposta dos fluxos de crédito a pequenos versus grandes tomadores de empréstimos. Nesta mesma concepção, Bernanke e Gertler (1995) propuseram que a teoria do canal de crédito de transmissão da política monetária sustenta que friç̧ões informacionais no mercado de crédito podem piorar durante períodos de crise.

Fuinhas (2002) também abordou o canal do crédito e os impulsos de política monetária, deixando de lado outros comportamentos dos agentes econômicos que, apesar de teoricamente terem relevância sobre o crédito, não conduzem a política monetária. Esse estudo descreve a teoria do canal do crédito, seus precursores, suas subdivisões e os modelos que justificam o racionamento do crédito, destacando, assim, questões associadas à economia da informação.

Nessa mesma linha, Carneiro, Salles e Wu (2006) analisaram o crédito como mecanismo de transmissão da política monetária. Verificou-se o crédito como condutor dos choques de demanda, por meio de balanço das organizações, como um "multiplicador financeiro" desses choques, através de movimentações da taxa de câmbio. Concluiu-se que a elevação de juros acarreta no aumento da atividade, via redução na demanda por crédito e, no nível de investimento. Ou seja, a cada 1\% de aumento na taxa de juros o total de crédito demandado reduz em, aproximadamente, 0,5\%.

Estudos como de lacoviello e Minetti (2008) também testaram a relação entre o canal de crédito e a política monetária, especialmente, empréstimos bancários e o mercado imobiliário. Ambos utilizaram a abordagem VAR para analisar esta questão em quatro países: Finlândia, Alemanha, Noruega e Reino Unido. Os resultados mostraram que há relação entre crédito, eficiência de financiamento habitacional e tipo de instituições ativas na prestação de hipoteca. Nesta mesma perspectiva, Machado, Ceretta e Vieira (2014) analisaram se as variáveis da política monetária exemplificam a concessão de crédito para o setor imobiliário. Neste estudo foi utilizada a técnica de Mínimos Quadrados Ordinários (MQO), que demonstrou que as variáveis de maior significância foram as diferenças das variáveis taxa de juros SELIC, a renda e o montante de dinheiro disponível no mercado, em suas respectivas defasagens.

Mello e Pisu (2010) também avaliaram o canal de transmissão de política monetária realizado por empréstimos bancários, porém, utilizando-se uma série temporal (dados mensais) mais ampla, entre dezembro de 1995 e junho de 2008. Os resultados encontrados dizem respeito à oferta de empréstimos e relaciona de forma negativa esta, à taxa de certificado de depósito interbancário, concluindo que existe sim um canal de empréstimos para a transmissão monetária. 
Bruna R. V. do Nascimento; Odilon J. de Oliveira Neto; Simone O. Rezende e Victor M. B.

Partindo de outra perspectiva, Linardi (2008), analisou por meio da aplicação do modelo vetorial de autorregressão (VAR), a relação entre a inadimplência dos empréstimos de bancos brasileiros e as variáveis político-monetárias. As variáveis utilizadas foram: a inadimplência (variável dependente) e a diferença do PIB real e PIB potencial, a variação do rendimento médio do pessoal ocupado, a taxa SELIC anualizada e a expectativa de inflação (variáveis independentes). Os resultados mostraram que em períodos de recessão econômica, os bancos públicos tornam-se mais vulneráveis aos choques macroeconômicos.

Auel e Mendonça (2011) apresentaram uma contribuição para a literatura empírica relacionada a canais de crédito nos países emergentes, com base em dados dos anos de 2002 a 2009, três conjuntos de modelos GMM (Generalized Method of Moments, traduzido para o português, Método dos Momentos Generalizado) são considerados para analisar a relevância de políticas monetárias nos canais de crédito no Brasil. O primeiro conjunto analisou os efeitos de choques nas variáveis de política monetária, o segundo considerou os efeitos das mesmas variáveis sobre o spread de crédito e o terceiro levou em conta os efeitos das mudanças nas condições do mercado de crédito sobre o produto. É realizada uma análise VAR e construído o modelo GMM, podendo constatar que os choques sobre a taxa de juros não são transmitidos para a economia de forma direta, mas por meio dos canais de crédito.

Em outra perspectiva, Schechtman e Gaglianone (2011) utilizaram as variáveis PIB, taxa de desemprego, inflação, taxa de juros e volume de crédito concedido para computar o risco de crédito das famílias, por meio de teste de estresse macroeconômico para o Brasil, nos anos de 1995 a 2009. Os resultados mostraram que o PIB e o crescimento de volume de crédito possuem efeitos negativos significativos sobre o risco de crédito e positivos, entre a taxa de desemprego e taxa de inflação.

Montes e Machado (2013) também verificaram a transmissão da política monetária através do canal de crédito no Brasil e ofereceram uma revisão da literatura sobre a inflação e segmentação da credibilidade e também sobre o mecanismo de transmissão da política monetária através do canal de crédito. Os autores desenvolveram um modelo teórico baseado em Bernanke e Blinder (1992) e buscaram evidências empíricas para a economia brasileira, utilizando mínimos quadrados ordinários (MQO). Os resultados apontaram que a oferta de crédito é estimulada quando a economia aquece e, além disso, encontrou-se evidências de que o canal de crédito funciona como um mecanismo de transmissão da política monetária.

Nessa mesma linha, Tavares, Montes e Guílen (2013) focaram em uma literatura sobre mecanismos de transmissão da política monetária pelos canais do crédito e de tomada de risco, e analisaram o impacto da política monetária sobre o processo de contratação de seguro. Verificou-se a influência da contratação desta modalidade de seguro sobre o spread de crédito no Brasil, obtendo resultados que apontaram que há influência da política monetária sobre o seguro e que ambos são relacionados positivamente.

Em outro contexto, Paranhos e Ribeiro (2014) verificaram a relação entre a inadimplência, e diversas variáveis econômicas, mais precisamente: a inflação, a taxa de 
p. 43 - Relação do emprego, da renda e das variáveis político-monetárias com as decisões de modalidades de crédito

desemprego, o número de falências decretadas, o rendimento médio dos ocupados, o PIB, o salário mínimo, a cotação do dólar, o crédito disponível para pessoas físicas, o crédito concedido a pessoas físicas, o percentual concedido, a taxa de juros nominal (SELIC), o spread bancário em operações para pessoas físicas, a demanda por crédito por pessoas físicas e o volume de vendas no varejo no período de março de 2007 a março de 2014 para verificar os níveis de inadimplência de pessoas físicas no Brasil. Com base nos resultados concluiu-se que a inadimplência possui relação positiva com o saldo de crédito, concessão de crédito, taxa SELIC, spread bancário, PIB e demanda por crédito. Por outro lado, a inadimplência relaciona-se negativamente com o Índice Nacional de Preços ao Consumidor Amplo (IPCA). Essa análise refere-se a um período trimestral. $\mathrm{Na}$ análise semestral, a inadimplência possui relação positiva apenas com o volume e a concessão de crédito. Já para o período de doze meses, a inadimplência relacionou-se positivamente com o saldo de crédito, o PIB e o percentual de crédito concedido.

Quanto à revisão de literatura vale destacar que alguns estudos se assemelham ao proposto no presente estudo. Esse é o caso de Gertler e Gilchrist (1993) e Bernanke e Gertler (1995), que apontaram os impactos do mercado do crédito na transmissão da política monetária. Diferente dessa abordagem, Fuinhas (2002) não considera alguns comportamentos dos detentores da riqueza que poderiam não conduzir à política monetária, focando na problemática do racionamento do crédito. Com base na problemática da elevação da taxa de juros a partir de 2005, Carneiro, Sales e Wu (2006) verificaram, através das movimentações na taxa de câmbio, que esse aumento acarreta numa redução do total de crédito demandado. Mas, dentre os estudos recentes, o que mais se destaca na linha do presente artigo é o estudo de Vieira, Roma e Ferreira (2014) que apresentou resultados importantes quanto à relação entre o endividamento das famílias e a taxa de juros SELIC.

\section{DADOS E PROCEDIMENTOS METODOLÓGICOS}

Com o intuito de alcançar a finalidade do presente estudo, que envolveu a verificação da influência das variáveis político-monetárias e do emprego e renda nas decisões sobre a modalidade de crédito, optou-se por uma pesquisa de natureza descritiva e abordagem quantitativa, que pode ser caracterizada pela mensuração dos resultados a partir da aplicação de modelos estatísticos, análise e interpretação dos dados. A análise quantitativa tem como foco principal a verificação da relação entre as variáveis dependentes e independentes, respeitando o rigor dos testes referentes aos modelos de regressão, que incluem: autocorrelação, homocedasticidade, multicolinariedade e normalidade.

No que se refere aos dados do estudo, foi utilizada uma série temporal, com observações mensais do período compreendido entre abril de 2007 e janeiro de 2016, totalizando 106 observações. O período foi definido baseado na disponibilidade dos dados das modalidades de crédito. Os dados foram obtidos em sites institucionais oficiais, mais precisamente no Departamento Econômico do Banco Central do Brasil (BCB), na Fundação Getúlio Vargas (FGV) e no Instituto Brasileiro de Geografia e Estatística (IBGE). 
Bruna R. V. do Nascimento; Odilon J. de Oliveira Neto; Simone O. Rezende e Victor M. B.

Vicente - p.44

As variáveis foram selecionadas para o estudo com base no suporte teórico da revisão de literatura disposta no item 2 desse artigo.

As principais modalidades de crédito do banco de dados do Banco Central do Brasil foram caracterizadas como variáveis dependentes. Por outro lado, as independentes constituem-se das principais variáveis relacionadas às políticas monetárias, ao trabalho e à renda. A tabela 1 apresenta as características básicas e fonte de coleta de dados referentes às variáveis em estudo.

Tabela 1 - Caracterização das variáveis do estudo

\begin{tabular}{|c|c|c|}
\hline Variáveis dependentes & Descrição & Fonte \\
\hline $\begin{array}{l}\text { Cartão de crédito rotativo } \\
\text { (CCREDR) }\end{array}$ & $\begin{array}{l}\text { Operações de financiamento do saldo devedor remanescente após vencimento da fatura } \\
\text { e operações de saque com pagamento à vista, em dinheiro, efetuadas na função crédito. }\end{array}$ & $\mathrm{BCB}$ \\
\hline $\begin{array}{l}\text { Cartão de crédito à vista } \\
\text { (CCREDAV) }\end{array}$ & $\begin{array}{l}\text { Corresponde às compras à vista realizadas no cartão de crédito e às compras parceladas } \\
\text { pelos lojistas (afiliados), em que não há incidência de juros. }\end{array}$ & $\mathrm{BCB}$ \\
\hline $\begin{array}{l}\text { Cartão de crédito } \\
\text { parcelado (CCREDP) }\end{array}$ & Compreende o parcelamento de compras realizadas com cartão de crédito. & $\mathrm{BCB}$ \\
\hline $\begin{array}{l}\text { Crédito não consignado } \\
\text { (NCSIG) }\end{array}$ & $\begin{array}{l}\text { Linha de crédito às pessoas físicas sem vinculação com aquisição de bem ou serviço, e } \\
\text { sem desconto em folha de pagamento. }\end{array}$ & $\mathrm{BCB}$ \\
\hline Crédito consignado (CSIG) & $\begin{array}{l}\text { O desconto da prestação é feito diretamente na folha de pagamento ou de benefício } \\
\text { previdenciário do contratante. }\end{array}$ & $\mathrm{BCB}$ \\
\hline $\begin{array}{c}\text { Cheque especial } \\
\text { (CHEQESP) }\end{array}$ & $\begin{array}{l}\text { Crédito rotativo vinculado à conta corrente, em que determinado limite de recursos é } \\
\text { disponibilizado para utilização pelo cliente em situações não programadas. }\end{array}$ & $\mathrm{BCB}$ \\
\hline Variáveis dependentes & Descrição & Fonte \\
\hline $\begin{array}{l}\text { Taxa básica de juros } \\
\text { (SELIC) }\end{array}$ & $\begin{array}{l}\text { A taxa média ajustada dos financiamentos diários apurados no Sistema Especial de } \\
\text { Liquidação e de Custódia (SELIC) para títulos federais. }\end{array}$ & $\mathrm{BCB}$ \\
\hline $\begin{array}{l}\text { Recolhimentos de } \\
\text { compulsórios (COMP) }\end{array}$ & $\begin{array}{l}\text { Representa certa parcela de depósitos a ser captada pelos bancos que serão mantidos } \\
\text { compulsoriamente no Banco Central. }\end{array}$ & $\mathrm{BCB}$ \\
\hline $\begin{array}{l}\text { Papel moeda em poder do } \\
\text { público (M1) }\end{array}$ & $\begin{array}{l}\text { É o saldo entre papel moeda emitido entre os encaixes do sistema bancário e os depósitos } \\
\text { à vista. Para o modelo, será utilizado o saldo no final do período. }\end{array}$ & $\mathrm{BCB}$ \\
\hline Títulos públicos (TIP) & $\begin{array}{l}\text { São os títulos emitidos pelo governo. Para a análise, será usado o saldo ao final do } \\
\text { período. }\end{array}$ & $\mathrm{BCB}$ \\
\hline $\begin{array}{l}\text { Índice Geral de Preços do } \\
\text { Mercado } \\
\text { (IGPM) }\end{array}$ & $\begin{array}{l}\text { Indicador que mede a evolução geral de preços na economia brasileira. O IGP-M é } \\
\text { composto pelo Índice de Preços ao Consumidor (IPC - peso de 30\%), Índice de Preços no } \\
\text { Atacado (IPA - peso de 60\%) e Índice Nacional de Construção Civil (INCC - peso de 10\%). } \\
\text { O período de coleta de preços para o índice se dá entre o dia } 21 \text { do mês anterior e o dia } \\
20 \text { do mês de referência. }\end{array}$ & FGV \\
\hline $\begin{array}{l}\text { Índice Nacional de Preços } \\
\text { ao Consumidor Amplo } \\
\text { (IPCA) }\end{array}$ & $\begin{array}{l}\text { Índice de Preços ao Consumidor que tem como unidades de coleta estabelecimentos } \\
\text { comerciais e de prestação de serviços, concessionária de serviços públicos e domicílios } \\
\text { (para levantamento de aluguel e condomínio). Representa o aumento ou queda do no } \\
\text { nível de preços. Trata-se do indicador de crescimento dos preços de um conjunto de bens } \\
\text { e serviços em um determinado período. }\end{array}$ & $\mathrm{BCB}$ \\
\hline Taxa de câmbio (CAMB) & Preço da moeda estrangeira em moeda nacional (real/dólar americano). & BCB \\
\hline $\begin{array}{l}\text { Renda média mensal } \\
\text { (RND) }\end{array}$ & Rendimento médio mensal de um trabalhador e rendimentos advindos de outras fontes. & IBGE \\
\hline $\begin{array}{l}\text { Taxa de desemprego } \\
\text { (DESEMP) }\end{array}$ & Índice de pessoas oficialmente desocupadas no Brasil. & IBGE \\
\hline $\begin{array}{l}\text { Produto Interno Bruto } \\
\qquad \text { (PIB) }\end{array}$ & $\begin{array}{l}\text { Soma (em valores monetários) de todos os bens e serviços finais produzidos numa } \\
\text { determinada região durante um período determinado. }\end{array}$ & $\mathrm{BCB}$ \\
\hline
\end{tabular}

Nota: Banco Central do Brasil (BCB); Fundação Getúlio Vargas (FGV) e; Instituto Brasileiro de Geografia e Estatística (IBGE). Fonte: BCB (2016), FGV (2016) e IBGE (2016). 
p. 45 - Relação do emprego, da renda e das variáveis político-monetárias com as decisões de modalidades de crédito

Ao visar atingir o objetivo da pesquisa, optou-se pela aplicação do teste de correlação para verificação da relação linear entre as variáveis em estudo, seguido da análise de regressão linear múltipla para verificar como a variável dependente modalidade de crédito se relaciona com as variáveis independentes de ordem monetária, de trabalho e renda. A seleção dos modelos foi definida pela técnica stepwise (ou análise por etapas), que tem por objetivo principal eliminar as variáveis não significantes estatisticamente no modelo de regressão múltipla geral. No caso da técnica stepwise, mesmo que a inclusão de variáveis esteja embasada na teoria, esta é limitada no que tange a possiblidade de multicolinariedade entre as variáveis selecionadas. O padrão geral do modelo regressão linear múltipla se baseou na seguinte equação:

$$
y=\beta_{0}+\beta_{1} x_{1}+\beta_{2} x_{2}+\cdots+\beta_{p} x_{p}+u_{t}
$$

Em que: $y$ é o valor estimado da variação da variável dependente; $\beta_{0}$ é a constante da regressão; $\beta_{1}, \beta_{2} \ldots, \beta_{p}$ referem-se às elasticidades da variável dependente em relação às variações nas independentes; e, $u_{t}$ é o termo de erro da regressão. Com a finalidade de analisar os dados foi utilizado o software Statistical Package for the Social Sciences (SPSS 20.0) para as análises de correlação e regressão linear múltipla. Vale destacar que foram respeitadas as particularidades e rigores estatísticos referentes aos testes selecionados, conforme pode ser observado na próxima seção desse estudo, que é constituída da análise e discussão dos resultados.

\section{ANÁLISES E DISCUSSÕES DOS RESULTADOS}

Os dados, resultados e discussões sobre a relação entre as modalidades de crédito a renda, o emprego e as variáveis de ordem econômico-monetárias são apresentados a seguir com a finalidade de atingir o objetivo principal do estudo.

Os resultados apresentados na Tabela 2 permitiram constatar uma associação negativa entre o produto interno bruto, o cartão de crédito rotativo ( $r=-0,501)$ e o cheque especial $(r=-0,251)$ e positiva com o cartão de crédito à vista $(r=0,390)$ e o crédito consignado $(r=0,259)$. Em contrapartida, se observou, também, uma associação negativa entre a renda e o cartão de crédito rotativo $(r=-0,419)$, o cartão de crédito parcelado $(r=-0,288)$, o crédito não consignado $(r=-0,419)$ e o cheque especial $(r=-$ 0,772 ) e uma associação positiva da renda apenas com o cartão de crédito à vista ( $r=$ 0,602). O resultado sugere que a renda e o crédito de curto prazo seguem a mesma direção, enquanto que essa mesma renda segue direção oposta ao crédito de longo prazo, o que corrobora as conclusões de Machado, Ceretta e Vieira (2014) que identificaram que um aumento na renda acarreta uma redução no volume de empréstimos de longo prazo concedidos.

Quanto à taxa de desemprego, constatou-se uma relação positiva desta com o cartão de crédito rotativo $(r=0,460)$, com o cartão de crédito parcelado $(r=0,245)$, com o crédito não consignado $(r=0,237)$ e com o cheque especial $(r=0,628)$ e uma relação negativa somente com o cartão de crédito à vista $(r=-0,594)$, ou seja, um aumento da taxa de desemprego tem uma relação inversa com o crédito de curto prazo, essa constatação reforça o resultado de Paranhos e Ribeiro (2014), que apesar observar pelo 
Bruna R. V. do Nascimento; Odilon J. de Oliveira Neto; Simone O. Rezende e Victor M. B.

ângulo da inadimplência como variável dependente, também concluiu que ao ampliar o desemprego têm-se mais pessoas físicas inadimplentes, o que as fazem recorrer com maior força aos canais de crédito de longo prazo.

A respeito do papel moeda em poder do público, verificou-se a associação positiva deste com o cartão de crédito à vista $(r=0,640)$ e uma relação negativa do mesmo com as modalidades: cartão de crédito rotativo $(r=-0,485)$, cartão de crédito parcelado $(r=-$ $0,339)$, crédito não consignado $(r=-0,455)$ e cheque especial $(r=-0,863)$, com destaque para a última modalidade, que é considerada uma forte relação linear. Essa mesma modalidade, cheque especial, apesar de níveis mais baixos de correlação, também apresentou associação negativa com os recolhimentos de compulsórios $(r=-0,195)$ e com o saldo dos títulos públicos ( $r=-0,337)$. Quanto ao crédito consignado, ressalta-se sua relação negativa com a taxa de juros Selic $(r=-0,221)$ e a taxa de câmbio $(r=-0,250)$, sugerindo que quanto maiores as taxas de juros e de câmbio, menores são as adesões das pessoas físicas ao crédito descontado na folha de pagamento.

Tabela 2 - Correlação linear de Pearson entre as variáveis em estudo

\begin{tabular}{|c|c|c|c|c|c|c|c|c|c|c|c|c|c|c|c|c|}
\hline & CCREDR & CCREDAV & CCREDP & NCSIG & CSIG & CHEQESP & PIB & SELIC & COMP & IPCA & CAMB & M1 & IGPM & DESEMP & RENDA & TIP \\
\hline CCREDR & 1 & $-0,596^{*}$ & $0,252^{*}$ & $0,341^{*}$ & $-0,077$ & $0,482 *$ & $-0,501 *$ & 0,005 & $-0,154$ & 0,092 & $-0,054$ & $-0,485^{*}$ & 0,12 & $0,460 *$ & $-0,419^{*}$ & $-0,068$ \\
\hline CCREDAV & & 1 & $-0,031 *$ & $-0,290 *$ & $0,231 * *$ & $-0,527 *$ & $0,390^{*}$ & $-0,058$ & 0,164 & $-0,05$ & $-0,035$ & $0,640^{*}$ & $-0,013$ & $-0,594^{*}$ & $0,602 *$ & 0,073 \\
\hline CCREDP & & & 1 & $0,349^{*}$ & $-0,016$ & $0,338^{*}$ & $-0,107$ & 0,021 & $-0,156$ & 0,04 & $-0,056$ & $-0,339^{*}$ & $-0,081$ & $0,245^{* *}$ & $-0,288^{*}$ & $-0,099$ \\
\hline NCSIG & & & & 1 & $0,281 *$ & $0,365^{*}$ & 0,016 & 0,008 & 0,026 & 0,046 & $-0,138$ & $-0,455^{*}$ & 0,002 & $0,237 * *$ & $-0,419^{*}$ & $-0,094$ \\
\hline CSIG & & & & & 1 & 0,074 & $0,259^{*}$ & $-0,221 * *$ & $* 0,185$ & 0,009 & $-0,250^{*}$ & $-0,023$ & $-0,151$ & $-0,110$ & $-0,055$ & $-0,092$ \\
\hline CHEQESP & & & & & & 1 & $-0,251^{*}$ & 0,063 & $-0,195 * *$ & * $-0,026$ & $-0,066$ & $-0,863^{*}$ & 0,059 & $0,628^{*}$ & $-0,772 *$ & $-0,337^{*}$ \\
\hline PIB & & & & & & & 1 & $-0,003$ & 0,013 & 0,016 & $-0,005$ & $0,207^{* *}$ & 0,051 & $-0,318^{*}$ & $0,304 *$ & 0,079 \\
\hline SELIC & & & & & & & & 1 & 0,124 & $0,194 * *$ & $* 0,201 * *$ & $-0,012$ & $0,253 *$ & 0,017 & 0,018 & 0,048 \\
\hline COMP & & & & & & & & & 1 & 0,171 & $-0,222 * *$ & 0,175 & 0,118 & $-0,14$ & 0,152 & 0,135 \\
\hline IPCA & & & & & & & & & & 1 & $-0,008$ & $-0,005$ & $0,404 *$ & 0,104 & $-0,036$ & $-0,001$ \\
\hline CAMB & & & & & & & & & & & 1 & 0,141 & 0,029 & $-0,027$ & 0,104 & $0,019^{* *}$ \\
\hline M1 & & & & & & & & & & & & 1 & $-0,003$ & $-0,751^{*}$ & $0,919^{*}$ & $0,372 *$ \\
\hline IGPM & & & & & & & & & & & & & 1 & $-0,03$ & 0,023 & $-0,062$ \\
\hline DESEMP & & & & & & & & & & & & & & 1 & $-0,769^{*}$ & $-0,333^{*}$ \\
\hline RENDA & & & & & & & & & & & & & & & 1 & $0,468^{*}$ \\
\hline TIP & & & & & & & & & & & & & & & & 1 \\
\hline
\end{tabular}

Notas: (CCREDR) Cartão de Crédito Rotativo, (CCREDAV) Cartão de Crédito Parcelado, (CCREDP) Cartão de Crédito Parcelado, (NCSIG) Crédito não Consignado, (CSIG) Crédito Consignado, (CHEQESP) Cheque Especial, (SELIC) Taxa Selic, (COMP) Recolhimento de Compulsórios, (M1) Papel moeda em poder do público, (TIP) Títulos Públicos, (IPCA) Índice de Inflação para o Consumidor Amplo, (CAMB) Taxa de Câmbio, (RND) Renda Média Mensal, (DESEMP) Taxa de Desemprego, (PIB) Produto Interno Bruto, (IGPM) Índice Geral de Preços do Mercado, $\left({ }^{*}\right)$ significante em nível de $1 \%$, e (**) significante ao nível de 5\%. Fonte: Dados da pesquisa (2016).

Na Tabela 3, estão expostos os modelos gerais de regressão linear múltipla, que incluem todas as variáveis do estudo. Os modelos explicam em, aproximadamente (observar percentual pelo valor do $\mathrm{R}^{2}$ ajustado multiplicado por cem), 43\% a variação do cartão de crédito rotativo (Modelo 1), 48\% a variação do cartão de crédito à vista (Modelo 2), $6 \%$ a variação do cartão de crédito parcelado (Modelo 3), 19\% a variação do crédito não consignado e consignado (respectivamente, Modelos 4 e 5), e $75 \%$ a variação do cheque especial (Modelo 6). Os resultados indicam que as variáveis independentes podem explicar em níveis significativos às variações referentes às principais modalidades de crédito utilizadas pelas pessoas físicas no Brasil. No entanto, os modelos gerais de regressão linear múltipla são penalizados, em razão da inclusão de variáveis independentes que não são estatisticamente significativas aos níveis de $1 \%$ e $5 \%$. 
p. 47 - Relação do emprego, da renda e das variáveis político-monetárias com as decisões de modalidades de crédito

Tabela 3 - Modelos de regressão linear múltipla com todas as variáveis independentes selecionadas em estudo

\begin{tabular}{|c|c|c|c|c|c|c|c|c|c|c|c|c|c|}
\hline \multicolumn{14}{|c|}{ Modalidade 1 - Cartão de Crédito Rotativo } \\
\hline C & $\begin{array}{c}\text { PIB } \\
\beta 1\end{array}$ & $\begin{array}{c}\text { SELIC } \\
\beta 2\end{array}$ & $\begin{array}{c}\text { TIP } \\
\beta 3\end{array}$ & $\begin{array}{c}\text { COMP } \\
\beta 4\end{array}$ & $\begin{array}{c}\text { IPCA } \\
\beta 2\end{array}$ & $\begin{array}{c}\text { CAMB } \\
\beta 6\end{array}$ & $\begin{array}{l}\text { M1 } \\
\beta 7\end{array}$ & $\begin{array}{c}\text { IGPM } \\
\beta 8\end{array}$ & $\begin{array}{c}\text { DESEM } \\
\beta 9\end{array}$ & $\begin{array}{c}\text { RND } \\
\beta 10\end{array}$ & $\begin{array}{c}\text { Estat. } \\
\qquad F\end{array}$ & $R^{2}$ & $R^{2 a j}$ \\
\hline 0,0136 & $-0,4650^{*}$ & $-0,0487$ & 0,0973 & $-0,1164$ & 0,0713 & $-0,0369$ & $-0,7389^{*}$ & $-0,038^{* * *}$ & 0,1479 & $0,4909^{* *}$ & 9,1151 & 0,4897 & 0,4359 \\
\hline$[4,4357]$ & {$[-5,7820]$} & {$[-0,6160]$} & {$[-1,108]$} & {$[-1,4502]$} & {$[0,8549]$} & {$[-0,4504]$} & {$[3,594]$} & {$[1,6659]$} & {$[1,2224]$} & {$[2,2538]$} & & & \\
\hline 0,0000 & 0,0000 & 0,5393 & 0,2708 & 0,1503 & 0,3948 & 0,6534 & 0,0005 & 0,0990 & 0,2246 & 0,0265 & 0,00000 & & \\
\hline \multicolumn{14}{|c|}{ Modalidade 2 - Cartão de Crédito à vista } \\
\hline C & $\begin{array}{c}\text { PIB } \\
\beta 1\end{array}$ & $\begin{array}{c}\text { SELIC } \\
\beta 2\end{array}$ & $\begin{array}{c}\text { TIP } \\
\beta 3\end{array}$ & $\begin{array}{c}\text { COMP } \\
\beta 4\end{array}$ & $\begin{array}{c}\text { IPCA } \\
\beta 2\end{array}$ & $\begin{array}{c}\text { CAMB } \\
\beta 6\end{array}$ & $\begin{array}{l}\text { M1 } \\
\beta 7\end{array}$ & $\begin{array}{c}\text { IGPM } \\
\beta 8\end{array}$ & $\begin{array}{c}\text { DESEM } \\
\beta 9\end{array}$ & $\begin{array}{c}\text { RND } \\
\beta 10\end{array}$ & $\begin{array}{c}\text { Estat. } \\
\text { F }\end{array}$ & $R^{2}$ & $R^{2 a j}$ \\
\hline 0,01682 & $0,2427^{*}$ & $-0,02274$ & $-0,1988^{* *}$ & 0,06983 & $-0,0284$ & $-0,0537$ & $0,5385^{*}$ & $-0,0310$ & $-0,1817$ & $-0,0181$ & 11,0645 & 0,5380 & 0,4894 \\
\hline$[3,012]$ & {$[3,1717]$} & {$[-0,302]$} & {$[-2,380]$} & {$[0,9140]$} & {$[-0,3583]$} & {$[-0,6902]$} & {$[2,7536]$} & {$[-0,3912]$} & {$[-1,5789]$} & {$[-0,0871]$} & & & \\
\hline 0,003 & 0,0020 & 0,7633 & 0,0193 & 0,3630 & 0,7209 & 0,4917 & 0,0071 & 0,6966 & 0,1177 & 0,9308 & 0,0000 & & \\
\hline \multicolumn{14}{|c|}{ Modalidade 3 - Cartão de Crédito Parcelado } \\
\hline C & $\begin{array}{c}\text { PIB } \\
\beta 1\end{array}$ & $\begin{array}{c}\text { SELIC } \\
\boldsymbol{\beta} 2\end{array}$ & $\begin{array}{c}\text { TIP } \\
\beta 3\end{array}$ & $\begin{array}{c}\text { COMP } \\
\beta 4\end{array}$ & $\begin{array}{c}\text { IPCA } \\
\beta 2\end{array}$ & $\begin{array}{c}\text { CAMB } \\
\beta 6\end{array}$ & $\begin{array}{l}\text { M1 } \\
\beta 7\end{array}$ & $\begin{array}{c}\text { IGPM } \\
\beta 8\end{array}$ & $\begin{array}{c}\text { DESEM } \\
\beta 9\end{array}$ & $\begin{array}{c}\text { RND } \\
\beta 10\end{array}$ & $\begin{array}{c}\text { Estat. } \\
\boldsymbol{F}\end{array}$ & $R^{2}$ & $\boldsymbol{R}^{2 a j}$ \\
\hline 0,016277 & $-0,0695$ & 0,04426 & 0,0038 & $-0,1205$ & 0,1128 & $-0,0371$ & $-0,515^{* * *}$ & $-0,1263$ & $-0,0429$ & 0,2001 & 1,6826 & 0,1505 & 0,0610 \\
\hline$[4,9222]$ & {$[-0,6703]$} & {$[0,4335]$} & {$[0,0337]$} & {$[-1,1634]$} & {$[1,0491]$} & {$[-0,3513]$} & {$[-1,9428]$} & {$[-1,1764]$} & {$[-0,2750]$} & {$[0,7120]$} & & & \\
\hline 0,0000 & 0,5043 & 0,6656 & 0,9732 & 0,2476 & 0,2968 & 0,7261 & 0,0550 & 0,2424 & 0,7839 & 0,4782 & 0,0960 & & \\
\hline \multicolumn{14}{|c|}{ Modalidade 4 - Crédito Não consignado } \\
\hline C & $\begin{array}{l}\text { PIB } \\
\beta 1\end{array}$ & $\begin{array}{c}\text { SELIC } \\
\beta 2\end{array}$ & $\begin{array}{c}\text { TIP } \\
\beta 3\end{array}$ & $\begin{array}{c}\text { COMP } \\
\beta 4\end{array}$ & $\begin{array}{c}\text { IPCA } \\
\beta 2\end{array}$ & $\begin{array}{c}\text { CAMB } \\
\beta 6\end{array}$ & $\begin{array}{l}\text { M1 } \\
\beta 7\end{array}$ & $\begin{array}{c}\text { IGPM } \\
\beta 8\end{array}$ & $\begin{array}{c}\text { DESEM } \\
\beta 9\end{array}$ & $\begin{array}{l}\text { RND } \\
\beta 10\end{array}$ & $\begin{array}{c}\text { Estat. } \\
\qquad F\end{array}$ & $R^{2}$ & $R^{2 a j}$ \\
\hline 0,0113 & 0,1093 & 0,0061 & 0,1155 & 0,0773 & 0,0537 & $-0,0569$ & $-0,436^{* * *}$ & $-0,0290$ & $-0,2402$ & $-0,2934$ & 3,4714 & 0,2676 & 0,1905 \\
\hline$[6,6854]$ & {$[1,1345]$} & {$[0,0639]$} & {$[1,0984]$} & {$[0,8032]$} & {$[0,5381]$} & {$[-0,5807]$} & {$[-1,7714]$} & {$[-0,2913]$} & {$[-1,6575]$} & {$[-1,1242]$} & & & \\
\hline 0,0000 & 0,2594 & 0,9492 & 0,2748 & 0,4239 & 0,5918 & 0,5628 & 0,0797 & 0,7715 & 0,1007 & 0,2637 & 0,0004 & & \\
\hline \multicolumn{14}{|c|}{ Modalidade 5 - Crédito Consignado } \\
\hline C & $\begin{array}{c}\text { PIB } \\
\beta 1\end{array}$ & $\begin{array}{c}\text { SELIC } \\
\beta 2\end{array}$ & $\begin{array}{c}\text { TIP } \\
\beta 3 \\
\end{array}$ & $\begin{array}{c}\text { COMP } \\
\beta 4\end{array}$ & $\begin{array}{c}\text { IPCA } \\
\beta 2\end{array}$ & $\begin{array}{c}\text { CAMB } \\
\beta 6\end{array}$ & $\begin{array}{l}\text { M1 } \\
\beta 7\end{array}$ & $\begin{array}{c}\text { IGPM } \\
\beta 8\end{array}$ & $\begin{array}{c}\text { DESEM } \\
\beta 9\end{array}$ & $\begin{array}{c}\text { RND } \\
\beta 10\end{array}$ & $\begin{array}{c}\text { Estat. } \\
\text { F }\end{array}$ & $R^{2}$ & $R^{2 a j}$ \\
\hline 0,0163 & $0,2925^{*}$ & $-0,172^{* * *}$ & $-0,0418$ & $0,1915^{* *}$ & 0,0866 & $-0,1361$ & 0,1448 & $-0,175^{* * *}$ & $-0,272^{* * *}$ & $-0,471^{* * *}$ & 3,4596 & 0,2670 & 0,1898 \\
\hline$[11,8343]$ & {$[3,0345]$} & {$[-1,8168]$} & {$[-0,3974]$} & {$[1,9898]$} & {$[0,8671]$} & {$[-1,3872]$} & {$[0,5879]$} & {$[-1,7551]$} & {$[-1,8808]$} & {$[-1,8071]$} & & & \\
\hline 0,0000 & 0,0031 & 0,0724 & 0,6919 & 0,0495 & 0,3880 & 0,1686 & 0,5580 & 0,0825 & 0,0631 & 0,0739 & 0,0007 & & \\
\hline \multicolumn{14}{|c|}{ Modalidade 6 - Cheque especial } \\
\hline C & $\begin{array}{c}\text { PIB } \\
\beta 1\end{array}$ & $\begin{array}{c}\text { SELIC } \\
\beta 2\end{array}$ & $\begin{array}{c}\text { TIP } \\
\beta 3\end{array}$ & $\begin{array}{c}\text { COMP } \\
\beta 4\end{array}$ & $\begin{array}{c}\text { IPCA } \\
\beta 2\end{array}$ & $\begin{array}{c}\text { CAMB } \\
\beta 6\end{array}$ & $\begin{array}{l}\text { M1 } \\
\beta 7\end{array}$ & $\begin{array}{c}\text { IGPM } \\
\beta 8\end{array}$ & $\begin{array}{c}\text { DESEM } \\
\beta 9\end{array}$ & $\begin{array}{c}\text { RND } \\
\beta 10\end{array}$ & $\begin{array}{c}\text { Estat. } \\
\qquad F\end{array}$ & $R^{2}$ & $R^{2 a j}$ \\
\hline 0,0136 & $-0,1115^{* *}$ & 0,0352 & $-0,0553$ & $-0,0338$ & $-0,0421$ & 0,0536 & $-1,0573^{*}$ & 0,0625 & $-0,0535$ & 0,2133 & 32,0174 & 0,7712 & 0,7471 \\
\hline$[4,3541]$ & {$[-2,0707]$} & {$[0,6641]$} & {$[-0,9403]$} & {$[-0,6281]$} & {$[-0,7541]$} & {$[0,9775]$} & {$[-7,6812]$} & {$[1,1215]$} & {$[-0,6607]$} & {$[1,4626]$} & & & \\
\hline 0,0000 & 0,0411 & 0,5082 & 0,3494 & 0,5315 & 0,4527 & 0,3308 & 0,0000 & 0,2649 & 0,5104 & 0,1469 & 0,0000 & & \\
\hline
\end{tabular}

Notas: $\left(^{*}\right)$ significante ao nível de $1 \%,(* *)$ significante ao nível de $5 \%,(* * *)$ significante ao nível de $10 \%$, [valor] teste t, (.) p-valor, (aj.) ajustado (CCREDR) Cartão de Crédito Rotativo, (CCREDAV) Cartão de Crédito Parcelado, (CCREDP) Cartão de crédito parcelado, (NCSIG) Crédito nã consignado, (CSIG) Crédito consignado, (CHEQESP) Cheque especial, (SELIC) Taxa Selic, (COMP) Recolhimento de compulsórios, (M1) Papel moedi em poder do público, (TIP) Títulos Públicos, (IPCA) Índice de Inflação para o Consumidor Amplo, (CAMB) Taxa de câmbio, (RND) Renda Médi: Mensal, (DESEMP) Taxa de desemprego, (PIB) Produto Interno Bruto, (IGPM) Índice Geral de Preços do Mercado.

Fonte: Dados da pesquisa (2016).

Apesar de não expostos na tabela 3, os valores estimados dos critérios de informação de Akaike (AIC) e bayesiano de Schwarz (SBC) penalizaram a capacidade de explicação dos modelos gerais (ajuste do modelo), o que pode ser verificado quando se compara o nível de explicação dos modelos apresentados na Tabela 4, que apresentam $\mathrm{R}^{2}$ ajustados superiores aos modelos da Tabela 3, em função do melhor ajuste dos mesmos.

O estudo segue com a apresentação da Tabela 4, na qual se visualizam os modelos de regressão linear múltipla (poder de explicação dado pelo $R^{2}$ ajustado), determinados a partir da seleção por etapas, que se caracteriza principalmente pela remoção das variáveis não estatisticamente significativas aos níveis de 1\% e 5\%.

O Modelo 1a da modalidade cartão de crédito rotativo é composto somente pela variável independente PIB. Apenas essa variável explica aproximadamente $25 \%$ da variação da modalidade de cartão de crédito rotativo, sendo esta uma relação negativa, ou seja, um aumento do PIB acarretaria na diminuição das compras no cartão de crédito rotativo (ver Tabela 4). Na sequência, apresenta-se o Modelo 1b, com a inclusão da 
Bruna R. V. do Nascimento; Odilon J. de Oliveira Neto; Simone O. Rezende e Victor M. B.

Vicente - p.48

variável papel moeda em poder do público (M1) que agrega aproximadamente 15\% de explicação para as variações do cartão de crédito rotativo, chegando a um total de $40 \%$ de explicação. Também pode ser visualizado na Tabela 4 o Modelo 1c, que agrega a variável renda ao modelo anterior (1b). Assim sendo, as três variáveis independentes que compõem o modelo $1 c$ explicam aproximadamente $44 \%$ da variação do cartão de crédito rotativo, apontando que uma variação de $1 \%$ no PIB $\left(b_{1}=-0,4802\right)$ e no papel moeda em poder público $\left(b_{7}=-0,8605\right)$ acarreta respectivamente uma variação negativa de aproximadamente $0,4802 \%$ e $0,8605 \%$ na variação do cartão de crédito rotativo, enquanto que uma variação de $1 \%$ na renda $\left(b_{10}=0,5174\right)$ acarretaria em uma variação positiva de $0,5174 \%$ dessa mesma modalidade de crédito.

No Modelo $2 \mathrm{a}$, que refere-se à modalidade cartão de crédito à vista, a variável independente papel moeda em poder do público apresenta a elasticidade $\left(b_{7}=0,6396\right)$, que indica o quanto as variações nesta variável implicam em alterações significativas nas compras realizadas no cartão de crédito à vista (ver Tabela 4). Vale ressaltar que a equação de regressão do Modelo 2 a explica aproximadamente $40 \%$ das variações do cartão de crédito à vista. No modelo $2 b$, que abrange a inclusão do PIB, se agrega aproximadamente $6 \%$ na explicação quanto à variação do uso do cartão de crédito à vista. No entanto, no modelo $2 \mathrm{c}$, ao se acrescentar a variável saldo de títulos públicos, tem-se um ganho de quase $10 \%$ de explicação, o que sugere que um aumento de $1 \%$ na variação do PIB $\left(B_{1}=0,2695\right)$, e do papel moeda em poder do público $\left(b_{7}=0,6556\right)$, acarretaria uma elevação da variação das compras no cartão de crédito à vista, em respectivamente $0,2695 \%$ e $0,6556 \%$, enquanto que a variação de $1 \%$ do saldo dos títulos públicos $\left(b_{3}=-\right.$ $0,1925)$ ocasionaria uma variação negativa no uso dessa mesma modalidade em $0,1925 \%$.

O modelo 3a foi o único selecionado pela técnica por etapas para a modalidade cartão de crédito parcelado (ver Tabela 4), ou seja, dentre as variáveis independentes selecionadas, apenas o saldo de moeda em poder do público é capaz de explicar $11 \%$ a variação nas compras parceladas no cartão de crédito. $O\left(b_{7}=0,3393\right)$ estimado sugere que uma variação de $1 \%$ no saldo de moeda em poder do público acarretaria uma redução de 0,3393\% na variação da modalidade cartão de crédito parcelado.

A respeito da modalidade crédito não consignado, nota-se segundo o modelo 4a, que apenas o papel moeda em poder do público explica em aproximadamente $20 \%$ a variação do crédito não consignado. Pela aplicação da técnica por etapas, apenas essa variável foi selecionada entre as independentes para essa modalidade de crédito. Estimado o $\left(b_{7}=-0,4545\right)$, espera-se que uma alteração em $1 \%$ no papel moeda em poder do público incidiria em uma variação negativa de $-0,4545 \%$ na variação do crédito não consignado.

Diferente da modalidade de crédito não consignado, as alterações na modalidade de crédito consignado são explicadas por dois modelos, conforme aplicação da técnica por etapas. São eles os modelos $5 a$ e $5 b$, expostos na Tabela 4 . O modelo $5 a$ é composto apenas pela variável independente PIB e explica em aproximadamente $6 \%$ a variação do crédito consignado. 0 modelo $5 b$ adiciona algo em torno de $6 \%$ de explicação com a inclusão da variável taxa de câmbio. No modelo $5 b$ as sensibilidades do crédito consignado quanto às alterações do PIB, e da taxa de câmbio são respectivamente $\left(b_{1}=\right.$ 
p. 49 - Relação do emprego, da renda e das variáveis político-monetárias com as decisões de modalidades de crédito

$0,2577)$ e $\left(b_{6}=-0,2484\right)$. Dessa forma, são fortes os indícios de que a variação do crédito consignado está relacionada positivamente com o PIB, e o aumento em $1 \%$ deste estaria positivamente associado a uma alteração de $0,2577 \%$ na variação do crédito consignado. Porém, uma possível variação de $1 \%$ na variação da taxa de câmbio levaria a uma queda de algo em torno de $0,2484 \%$ na variação do crédito consignado.

O modelo 6a foi o único selecionado pela técnica por etapas para a modalidade cheque especial. Neste modelo, apenas a variável papel moeda em poder do público explica aproximadamente $75 \%$ das variações dessa modalidade de crédito cheque especial. Ao observar o $\left(b_{7}=-0,8635\right)$ estimado para o papel moeda em poder do público (M1), o modelo sugere ainda variação de $1 \%$ nesta variável independente acarreta uma variação negativa de aproximadamente $0,8635 \%$ na modalidade cheque especial.

Vale destacar que a verificação dos resíduos do modelo de regressão pela estatística K-S (Kolmogorov-Smirnov) sugere que os modelos expostos na Tabela 4 apresentam distribuição normal, ou seja, a frequência que se espera do modelo é igual à observada, o que contribui para a afirmação da capacidade preditiva dos mesmos. Verificou-se também valores muito próximos a dois, para estatística $d$ de DW (DurbinWatson), assim sendo, sugere-se que os resíduos dos modelos de regressão estimados e apresentados na Tabela 4 não possuem problemas de autocorrelação.

Tabela 4 - Modelos de regressão linear com as variáveis independentes selecionadas pela técnica stepwise

\begin{tabular}{|c|c|c|c|c|c|c|}
\hline \multicolumn{7}{|c|}{ Modalidade 1 - Cartão de Crédito Rotativo } \\
\hline \multicolumn{7}{|c|}{ Modelo 1a } \\
\hline C & $\begin{array}{l}\text { PIB } \\
81\end{array}$ & $\begin{array}{c}\text { Estat. } \\
\qquad F\end{array}$ & $R^{2}$ & $R^{2 a j}$ & & \\
\hline $\begin{array}{l}0,0142 \\
{[6,310]} \\
0,0000\end{array}$ & $\begin{array}{c}-0,5010^{*} \\
{[-5,904]} \\
0,0000\end{array}$ & $\begin{array}{c}34,8514 \\
0,0000\end{array}$ & 0,2510 & 0,2438 & & \\
\hline \multicolumn{7}{|c|}{ Modelo $1 b$} \\
\hline C & $\begin{array}{l}\text { PIB } \\
81\end{array}$ & $\begin{array}{l}\text { M1 } \\
67\end{array}$ & $\begin{array}{c}\text { Estat. } \\
F\end{array}$ & $R^{2}$ & $R^{2 a j}$ & \\
\hline $\begin{array}{c}0,0160 \\
{[7,8243]}\end{array}$ & $\begin{array}{l}-0,4187^{*} \\
{[-5,3792]}\end{array}$ & $\begin{array}{c}-0,3980^{*} \\
{[-5,1134]}\end{array}$ & 34,7126 & 0,4030 & 0,3910 & \\
\hline \multicolumn{7}{|c|}{ Modelo 1c } \\
\hline C & $\begin{array}{l}\text { PIB } \\
61\end{array}$ & $\begin{array}{l}\text { M1 } \\
82\end{array}$ & $\begin{array}{l}\text { RND } \\
610\end{array}$ & $\begin{array}{c}\text { Estat. } \\
\qquad F\end{array}$ & $R^{2}$ & $R^{2 a j}$ \\
\hline $\begin{array}{c}0,0182 \\
{[8,4400]}\end{array}$ & $\begin{array}{c}-0,4802^{*} \\
{[-6,0649]}\end{array}$ & $\begin{array}{c}-0,8605^{*} \\
{[-4,5105]}\end{array}$ & $\begin{array}{c}0,5174^{*} \\
{[2,6409]}\end{array}$ & 26,8089 & 0,4409 & 0,4409 \\
\hline 0,0000 & 0,0000 & 0,0000 & 0,0096 & 0,0000 & & \\
\hline
\end{tabular}

Continua... 
Bruna R. V. do Nascimento; Odilon J. de Oliveira Neto; Simone O. Rezende e Victor M. B. Vicente - p.50

...continuação

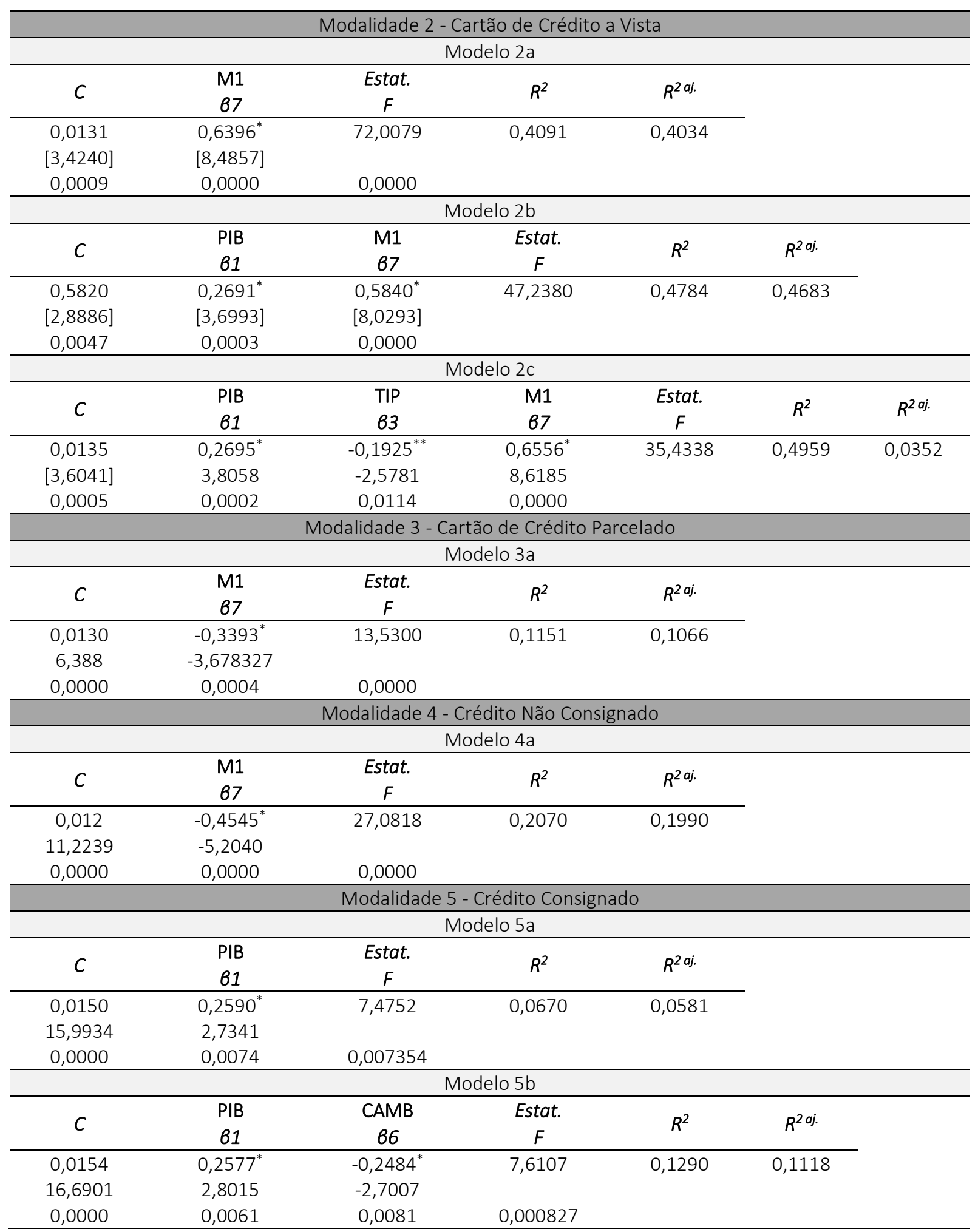

Continua... 
p. 51 - Relação do emprego, da renda e das variáveis político-monetárias com as decisões de modalidades de crédito

... conclusão

\begin{tabular}{ccccc}
\hline \multicolumn{5}{c}{ Modalidade 6 - Cheque Especial } \\
\hline$C$ & M1 & Estat. & $R^{2}$ & $R^{2 a j .}$ \\
\hline 0,012 & $B 7$ & $F$ & 0,7456 & 0,7431 \\
6,27027 & $-0,8635^{*}$ & 304,7521 & & \\
0,0000 & $-17,4572$ & & & \\
\hline
\end{tabular}

Notas: $\left(^{*}\right)$ significante ao nível de $1 \%$, [valor] teste $t$, (.) p-valor, (aj.) ajustado, (CCREDR) Cartão de Crédito Rotativo, (CCREDAV) Cartão de Crédito Parcelado, (CCREDP) Cartão de Crédito Parcelado, (NCSIG) Crédito Não Consignado, (CSIG) Crédito Consignado, (CHEQESP) Cheque Especial, (SELIC) Taxa Selic, (COMP) Recolhimento de compulsórios, (M1) Papel moeda em poder do público, (TIP) Títulos públicos, (IPCA) Índice de Inflação para o Consumidor Amplo, (CAMB) Taxa de Câmbio, (RND) Renda Média Mensal, (DESEMP) Taxa de desemprego, (PIB) Produto Interno Bruto, (IGPM) Índice Geral de Preços do Mercado.

Fonte: Dados da pesquisa (2016).

Em suma, algumas variáveis como o PIB, o papel moeda em poder do público, a renda, o saldo dos títulos públicos e taxa de câmbio influenciam significativamente a decisão pela modalidade de crédito, o que concorda com o exposto por Tavares, Montes e Guílen (2013). Ao contrário do presente estudo, Montes e Machado (2013) apresentaram como variavel independente o crédito como transmissor da política monetária. Os resultados apontaram que as modalidades de crédito se relacionam estatisticamente com as políticas monetárias.

Apesar de Auel e Mendonça (2011) também constatarem uma relação do crédito com a taxa de juros, faz-se importante ressaltar que no presente estudo as modalidades de crédito selecionadas não são estatisticamente relacionadas ao recolhimento de compulsórios, a inflação e a taxa de desemprego, e, portanto, não sofrem influências com as variações das mesmas. Destaca-se ainda que este estudo agregou valor no que tange ao tema e aos demais estudos teórico-empíricos publicados em periódicos nacionais, principalmente por considerar as principais modalidades de crédito utilizadas por pessoas físicas no Brasil.

\section{CONSIDERAÇÕES FINAIS}

O presente estudo teve como objetivo verificar a relação entre variáveis políticomonetárias, o trabalho e a renda com as decisões quanto à modalidade de crédito das pessoas físicas no Brasil entre 2007 e 2016. Concluiu-se com base nos resultados da pesquisa que as variáveis PIB, papel moeda em poder do público e renda são as que melhor explicam as variações do cartão de crédito rotativo. Já para a modalidade cartão de crédito à vista o PIB, o papel moeda em poder do público e saldo dos títulos públicos são quem melhor explicam as alterações desta.

Para o crédito consignado, as variáveis independentes PIB e taxa de câmbio são as que se relacionam diretamente com as alterações desta modalidade. Quanto à modalidade de crédito cheque especial, ressalta-se o grande poder de explicação das suas alterações pela variação do papel moeda em poder do público. Neste contexto, foi 
Bruna R. V. do Nascimento; Odilon J. de Oliveira Neto; Simone O. Rezende e Victor M. B. Vicente - p.52

verificada uma relação negativa entre as variáveis, cheque especial e papel moeda em poder do público.

Pode-se observar, ainda, que as variáveis independentes de ordem políticomonetária, de emprego e de renda que mais se relacionam com as decisões das principais modalidades de crédito utilizadas pelas pessoas físicas no Brasil são o PIB, o papel moeda em poder do público, a renda, o saldo dos títulos públicos e a taxa de câmbio, o que permite concluir que essas variáveis são as que mais impactam significativamente na escolha da modalidade de crédito, o que permitiu atingir o objetivo principal do presente estudo.

Em contrapartida, as variáveis em estudo que não se relacionaram estatisticamente com as modalidades de crédito selecionadas foram: o recolhimento de compulsórios, o IGPM, o IPCA, a taxa de desemprego e a taxa de juros. No entanto, sugere-se que a taxa de desemprego não esteja relacionada com a modalidade de crédito em razão de essa ser intrinsicamente inserida no conjunto da variável renda.

Vale ressaltar que para se chegar a um nível melhor de explicação para as variações das modalidades de crédito deve-se levar em conta que fatores comportamentais do indivíduo que podem alterar a decisão pelas mesmas, incluindo-se elementos como o planejamento financeiro. Portanto, recomenda-se que em futuras pesquisas sejam incluídas variáveis comportamentais que, poderão contribuir para melhor explicar a variação e a escolha da modalidade de crédito pelas pessoas físicas no Brasil.

\section{REFERÊNCIAS}

AUEL, M. C; MENDONÇA, H. F. Macroeconomic relevance of credit channels: Evidence from an emerging economy under inflation targeting. Economic Modelling, v. 28, n. 3, p. 965-979, 2011.

BANCO CENTRAL DO BRASIL. Evolução do Mercado de Crédito. Relatório de Economia Bancária e Crédito. Brasília, p. 1-117. Dez. 2013. Disponível em: <http://www.bcb.gov.br/pec/depep/spread/rebc_2013.pdf>. Acesso em: 11 jun. 2015.

BANCO CENTRAL DO BRASIL. Política Monetária e Operações de Crédito do SFN. Disponível em: <https://www.bcb.gov.br/?ECOIMPOM>. Acesso em: 10 out. 2015.

BERNANKE, B; BLINDER, A. The federal funds rate and the channels of monetary transmission. The American Economic Review, p. 901-921, 1992.

BERNANKE, B; GERTLER, M. Inside the black box: The credit channel of monetary policy transmission. Journal of Economic Perspectives, v. 9, p. 27-48, 1995.

CARNEIRO, D. D; SALLES, F. M; WU, T. Y. H. Juros, câmbio e as imperfeições do canal do crédito. Revista de Economia Aplicada, Rio de Janeiro, v. 1, n. 10, p. 7-23, jan./mar, 2006.

DEPARTAMENTO ECONÔMICO DO BANCO CENTRAL. Sistema Gerenciador de Séries Temporais. Brasília, 2014. Disponível em: <https://www3.bcb.gov.br/sgspub/ 
p. 53 - Relação do emprego, da renda e das variáveis político-monetárias com as decisões de modalidades de crédito

consultarvalores/consultarValoresSeries.do?method=consultarValores>. Acesso em: 10 out. 2015.

DOUAT, J. C. Desenvolvimento de modelo para administração de carteiras de crédito a pessoas jurídicas em um banco comercial com base na teoria da diversificação de riscos. Tese de doutorado. 1994. 154 f. Tese (Doutorado). Curso de Doutorado em Administração, Fundação Getúlio Vargas - FGV, São Paulo, 1994.

FUINHAS, J. A. O canal do crédito e a política monetária. Departamento de Gestão e Economia (DGE), Universidade da Beira Interior, 2002.

FUNDAÇÃO GETÚLIO VARGAS (Rio de Janeiro). Índices Gerais de Preços. Disponível em:<http://portalibre.fgv.br/main.jsp?lumChannelld=4028808 11D8 E34B9011D92B6160B0D7D>. Acesso em: 14 mai. 2016.

GERTLER, M; GILCHRIST, S. The role of credit market imperfections in the monetary transmission mechanism: Arguments and evidence. Scandinavian Journal of Economics, $v$. 95, p. 43-64, 1993.

IACOVIELLO, M.; MINETTI, R. The credit channel of monetary policy: Evidence from the housing market. Journal of Macroeconomics, v. 30, n. 1, p. 69-96, 2008.

INSTITUTO BRASILEIRO DE GEOGRAFIA E ESTATÍSTICA - IBGE. Notas metodológicas. Rio de Janeiro.

LINARDI, F. M. Avaliação dos Determinantes Macroeconômicos da Inadimplência Bancária no Brasil. 2008. 64 f. Dissertação (Mestrado) - Curso de Mestrado em Economia, Faculdade de Ciências Econômicas - UFMG, Belo Horizonte, 2008.

MACHADO, M. E. R; CERETTA, P. S.; VIEIRA, K. M. A relação entre as variáveis macroeconômicas e a concessão de crédito no mercado imobiliário brasileiro. Revista de Gestão, Finanças e Contabilidade, Salvador, v. 4, n. 3, p.64-84, set./dez, 2014. Disponível em: <http://www.revistas.uneb.br/index.php/financ/ article/view/778/665>. Acesso em: 11 jun. 2015.

MELLO, L.; PISU, M. The bank lending channel of monetary transmission in Brazil: A VECM approach. The Quarterly Review of Economics and Finance, v. 50, p. 50-60, 2010.

MONTES, G. C.; MACHADO, C. C. Credibility and the credit channel transmission of monetary policy theoretical model and econometric analysis for Brazil. Journal of Economic Studies, v. 40, n. 4, p. 469-492, 2013.

PARANHOS, L. S.; RIBEIRO, J. L. D. Interferência do ambiente macroeconômico na inadimplência de pessoas físicas no Brasil. 2014. 26 f. Trabalho de Conclusão de Curso (Graduação) - Curso de Engenharia de Produção, Universidade Federal do Rio Grande do Sul, Porto Alegre, 2014.

SCHECHTMAN, R; GAGLIANONE, W. P. Macro Stress Testing of Credit Risk Focused on the Tails. 241. ed. Brasília: Banco Central do Brasil, 2011. Disponível em: <http://www.bcb.gov.br/pec/wps/ingl/wps241.pdf 2>. Acesso em: 30 abr. 2016.

SANDRONI, P. Novíssimo dicionário da economia. São Paulo. Best Seller, 1999. 
Bruna R. V. do Nascimento; Odilon J. de Oliveira Neto; Simone O. Rezende e Victor M. B.

Vicente - p.54

SCHRICKEL, K. W. Análise de crédito: concessão e gerência de empréstimos. 2. Ed., SÃO PAULO: ATLAS, 1995.

TAVARES, D. P.; MONTES, G. C.; GUILLÉN, O. T. C. Transmissão da política monetária pelos canais de tomada de risco e de crédito: uma análise considerando os seguros contratados pelos bancos e o spread de crédito no Brasil. Revista Brasileira de Economia, Rio de Janeiro, v. 67, n. 3, p.337-353, jul./set, 2013.

VIEIRA, A. L. B. D; ROMA, C. M. S; FERREIRA, B. P. O custo do crédito pessoal em relação ao nível de endividamento das famílias brasileiras e à taxa de juros Selic. Revista Economia e Gestão, Belo Horizonte, v. 14, n. 36, p.138-160, jul./set, 2014.

YEAGER, F. C. Personal Bankruptcy and Economic Stability. Southern Economic Journal. USA, p. 96-102. Jul., 1974. 